\title{
Analogical effects in regular past tense production in Dutch
}

MIRJAM ERNESTUS AND HARALD BAAYEN

\section{Abstract}

This study addresses the question to what extent the production of regular past tense forms in Dutch is affected by analogical processes. We report an experiment in which native speakers of Dutch listened to existing regular verbs over headphones, and had to indicate which of the past tense allomorphs, te or de, was appropriate for these verbs. According to generative analyses, the choice between the two suffixes is completely regular and governed by the underlying [voice]-specification of the stem-final segment. In this approach, no analogical effects are expected. In connectionist and analogical approaches, by contrast, the phonological similarity structure in the lexicon is expected to affect lexical processing. Our experimental results support the latter approach: all participants created more nonstandard past tense forms, produced more inconsistency errors, and responded more slowly for verbs with stronger analogical support for the nonstandard form. ${ }^{1}$

\section{Introduction}

A great many studies have addressed the question how to account for regular and irregular word formation. In the traditional view (e.g. Halle 1973; Aronoff 1976; Pinker and Prince 1988; Marcus et al. 1995; Pinker 1999; Marcus 2001), regular complex forms are the result of productive morphological rules. Irregular complex forms fundamentally differ from the regular forms in that they must be stored in the speakers' mental lexicons and cannot be created by means of rules.

In contrast to this traditional view of the division of labor between rule and rote, many researchers (e.g. Bybee 1985, 2001; Skousen 1989, 1993; MacWhinney and Leinbach 1991; Daelemans et al. 1994; Seidenberg and Hoeffner 1998; Plunket and Juola 1999; Plaut and Gonnerman 2000; Seidenberg and Gonnerman 2000; Ramscar 2002) argue that both 
irregular and regular complex forms are available in the speakers' lexicons, and that no lexicon-independent rules are required. In these approaches, new forms are extrapolated from the lexicon either by similarity-based general analogical processes (Skousen's AML, Daelemans' TiMBL) or by artificial neural networks in which rules and representations are merged. In what follows, we will refer to these schools as analogical accounts, since they assume that the similarity structure in the data is of crucial importance.

The production of the past tense in English has figured as a testing ground for ascertaining the merits of the rule-based and analogy-based accounts (e.g. Marcus et al. 1995; Pinker and Prince 1991; Pinker 1991, 1997, 1999; Jaeger et al. 1996; Rumelhart and McClelland 1986; Albright and Hayes 2003). The aim of the present paper is to contribute to the debate on the role of analogy in word formation. We also call attention to the production of past tense forms, but, unlike abovementioned studies, we do not concentrate on the differences or similarities between regular and irregular past tense forms, but on the possibility that analogical processes pervade even completely regular past tense production, irrespective of irregular past tense formation.

The allomorphy of the Dutch past tense suffix constitutes a classical example of a completely regular simple morphological rule in Dutch morphology. Past tense forms are created by suffixing the allomorphs /ta/ te or /da/ de to the verb stem. The allomorph /ta/ is added when the stem ends in an underlyingly voiceless obstruent, or in other words, when the stem ends in a voiceless obstruent before the infinitive suffix /ən/ en. The suffix /də/ is suffixed elsewhere (e.g. Trommelen and Zonneveld 1979: 119; Wetzels 1982: 125; Booij 1995: 61). This is illustrated in (1). We refer to the past tense forms that obey this simple rule as the standard forms, since these forms are correct according to the Dutch spelling conventions. They contain the standard, conventionalized suffix. Note that this terminology implies that the term standard suffix sometimes refers to [tə] and sometimes to [də], depending on the verb stem. The standard forms are stored in the speakers' lexicon, as appears from Baayen, Schreuder, De Jong, and Krott (2002) and Baayen et al. (2003).

(1) Verb stem

$\begin{array}{lll}\text { rook } & / \text { rok/ } & \text { 'smoke' } \\ \text { stop } & / \text { stop/ } & \text { 'stop' } \\ \text { klaag } & / \mathrm{klay} / & \text { 'complain' } \\ \text { roof } & / \mathrm{rov} / & \text { 'steal' } \\ \text { kam } & / \mathrm{kam} / & \text { 'comb' }\end{array}$

Singular past tense form

$\begin{array}{lll}\text { rookte } & \text { /roktə/ } & \text { 'smoked' } \\ \text { stopte } & \text { /stoptə/ } & \text { 'stopped' } \\ \text { klaagde } & \text { /klaydə/ } & \text { 'complained' } \\ \text { roofde } & \text { /rovdə/ } & \text { 'stole' } \\ \text { kamde } & \text { /kamdə/ } & \text { 'combed' }\end{array}$


The experiment presented in this article is a follow-up of two previous experiments on regular past tense production in Dutch. The first experiment (Ernestus and Baayen 2003) is similar to Berko's (1958) wug/wugs experiments. Berko presented pseudo-words to English speaking children, such as wug, asking them to create the plural forms of these words (wugs). The children consistently added the appropriate suffixes to the new words. This result is generally interpreted as supporting the view that children have morphological rules at their disposal. In this first experiment on past tense production in Dutch, we presented native speakers of Dutch with the stems of pseudo-words, for example, [daup], [dorx], and [dint], asking them to create the past tense forms of these pseudo-verbs. Like the children in Berko's experiment, our participants were able to perform this task: they were able to create past tense forms. At first sight, these results constitute just another piece of evidence for the existence of morphological rules. However, the facts are not that simple.

From a rule-based perspective, it is in fact surprising that the participants were able to perform this task at all. Their task was far more complicated than the task that the children had to perform in Berko's experiment. Like the children in Berko's experiment, our participants had to choose between affixes, but unlike the children, they did not have enough information at their disposal to simply apply the morphological rule. Application of the rule depends on the availability of the underlying [voice]-specification of the stem-final obstruent. This information was not available to our participants. They heard the first person singular present tense forms of the pseudo-verbs, which do not allow participants deduction of the underlying [voice]-specification of the stem-final obstruents. The stem-final obstruents were word-final in these forms, and all wordfinal obstruents in Dutch are realized as voiceless (a phenomenon often referred to as "final devoicing"). Since pseudo-verbs do not have lexical representations, the participants could also not retrieve the underlying [voice]-specifications from their mental lexicon.

Inspection of the created past tense forms showed that the participants based their choice between te and de on the phonological neighborhoods for the presented pseudo-verbs. They tended to choose te for a given pseudo-verb if the majority of phonological neighbors underlyingly end in voiceless obstruents, and they tended to choose $d e$ if the majority of neighbors underlyingly end in voiced obstruents. The relevant phonological neighbors end in an obstruent of the same manner and place of articulation as the experimental verb, and their final obstruent is preceded by consonants of the same sonority, and vowels of the same phonological length as in the experimental verb. We will refer to these phonological neighbors that affect processing as the analogical, phonological gang. 
In conclusion, the participants based their choice between the two past tense allomorphs on analogy. In Ernestus and Baayen (i.p.), we show that participants are also influenced by the analogical gangs when final obstruents in the experiment have some acoustic characteristics of voiced obstruents, that is, when the signal provides information of the underlying [voice]-specifications of the final obstruents.

Rule-based theories might offer the following explanation for the data from this experiment with pseudo-verbs. The participants may first have determined the underlying [voice]-specifications of the pseudo-verbs by means of analogy. Once analogical processes have delivered an underlying [voice]-specification, this specification completes the input for the symbolic rule, which can now attach [tə] after underlyingly voiceless obstruents and [də] after underlyingly voiced obstruents.

Rule-based accounts predict that when speakers do have access to the underlying [voice]-specification of the stem-final obstruent, they should not rely on analogy. In other words, analogical effects should not be observed for existing words. When speakers have to create the past tense forms of existing words, they do know the underlying [voice]specifications of the stem-final obstruents, since these specifications are stored in their mental lexicons. Having retrieved the stem from memory, they can simply apply the rule without analogy coming into play.

Ernestus and Baayen (2001) is a first, off-line study investigating whether speakers indeed do not show analogical effects when they create the past tense forms of existing verbs. The participants in that experiment heard the first person singular present tense forms of existing verbs, instead of pseudo-verbs, and they were again asked to create the past tense forms. Contrary to the prediction of the rule-based account, this experiment again revealed analogical effects. The participants did not always use the past tense allomorph that one would expect given the underlying [voice]-specification of the final obstruent in standard Dutch. They tended to produce an unexpected past tense form when a verb underlyingly ends in a voiced obstruent, while most words in the analogical gang of phonologically similar words underlyingly end in voiceless obstruents. In this case, participants tend to attach [tə] instead of the expected [də]. Similarly, participants tend to attach [do] instead of the expected [to] to a verb with an underlyingly voiceless final obstruent for which the phonological gang favors [də]. For instance, several participants reported dubte as the past tense form for / $\mathrm{drb} / d u b$ 'waver,' and bliefte as the past tense form for /bliv/ blief 'like.' Conversely, they created juichde as the past tense form for /jœyx/ juich 'cheer.'

Proponents of rule-based accounts might argue that these results only hint at the extension of analogical effects to existing words. Analogical 
effects might have emerged only because some participants did not know the underlying [voice]-specifications for all stem-final obstruents. Several participants were speakers of varieties of Standard Dutch in which all fricatives tend to be realized as voiceless. Such speakers might only distinguish between stems underlyingly ending in voiced and voiceless fricatives on the basis of the spellings of these stems. If these spellings are not firmly stored in their mental lexicons, these speakers might be uncertain about the underlying [voice]-specification of the stem-final obstruent. If so, they would be forced to fall back on analogy. Moreover, some of the words presented in the experiment are fairly low-frequency verbs. For at least some participants, these words might effectively have been pseudoverbs, for which they consequently had to fall back on analogy in order to determine the most likely underlying [voice]-specification for the stemfinal obstruent.

The experiment that we report in this article is a direct follow-up of this experiment. It differs in three respects. First, we presented plural present tense forms to our participants, instead of singular present tense forms. Plural present tense forms in Dutch consist of the verb stem plus the suffix /ən/ en. In these forms, the stem-final obstruent is realized in accordance with its underlying [voice]-specification. The participants, therefore, could determine the underlying [voice]-specification of the stem-final obstruents simply on the basis of the acoustic signal. They are literally told over the headphones what the underlying [voice]-specification is.

Second, we distinguish three groups of participants. The first group of participants make a fairly systematic distinction between underlyingly voiced and voiceless fricatives. We refer to these participants as the $[+\mathrm{F}]$ group. They should be able to easily perceive the difference between the voiced and voiceless variants of all types of obstruents, and consequently they should be able to apply the rule in all cases. It is for these participants that the rule-based account predicts no effect of analogy. The second group of participants consists of speakers who do not make any distinction between voiced and voiceless fricatives. This group will be referred to as the $[-\mathrm{F}]$ group. The speakers of this group may have problems determining the standard past tense suffix for stems with final fricatives, since they may be uncertain about the underlying [voice]specifications of these final obstruents. Under the rule-based account, these are the participants for which analogical effects might be observed for fricative-final stems. The third group of participants $([ \pm F])$ realizes the distinction, but does not do so systematically.

Third, we asked our participants to perform two tasks. They first had to make their choice between [də] and [tə] known by pressing a te button or a de button. Following their button-press, they had to write down 
the past tense form. In this way, we obtained four dependent variables for every verb: the participants' choices as reflected by the written forms, the differences between the choices reflected by the written forms and by the button presses, the time the participants needed to press a button, and the proportion of trials for which the participants produced time-out errors.

This experiment allows us to investigate whether participants still show analogical effects, that is, effects of gangs of phonologically similar words, under these new experimental conditions, which is not expected under a rule-based account. That is, the experiment allows us to investigate whether the rule-based account is correct in that speakers might reveal effects of analogy only when, for whatever reasons unrelated to analogy, they do not have access to the underlying [voice]-specification of the stemfinal obstruent. To falsify this rule-based account, we have to show that the phonological gangs correctly predict for which words participants produce nonstandard past tense forms. Similarly, analogical gangs affecting the reaction times across the board, even for standard past tense forms, would count against the rule-based approach.

This new experiment will also allow us to investigate the appropriateness of analogical models, theories that assign a key role to the analogical similarity structure of the lexicon, and that do not posit separate morphological rules. Broadly speaking, we can distinguish two classes of analogical approaches, symbolic classifiers, and subsymbolic classifiers. The first class comprises instance-based models, of which Daelemans' TiMBLE (Daelemans et al. 1994, 2001) and Skousen's AML $(1989,1993)$ have proved to be especially useful for the analysis of linguistic data. These two symbolic models make use of an instance base of stored representations. For our data, this instance base can be conceived of as a lexicon of verbs, which, for each verb, specifies the phonological properties of the stem and the past tense allomorph required by this verb. In addition to such an instance base, AML and TiMBL supply a classification algorithm. This classification algorithm determines, for a given verb (existing or nonexisting), which verbs in the lexicon are most similar and may form an analogical gang. The classification algorithm assigns a probability to each of the two allomorphs equal to the proportion of verbs in such an analogical gang in which they are realized. The algorithm selects the allomorph with the highest probability as the most likely choice.

In standard applications of these models, the analogical classification algorithm is called upon only when the required past tense form is not available in the lexicon. In other words, from a psycholinguistic perspective, we are dealing with a cascaded model in which analogy applies only when retrieval from memory fails. Baayen, Burani, and Schreuder (1997) 
and Baayen, Dijkstra, and Schreuder (1997), however, argue that it is unfruitful to stagger memory retrieval and computation. They present evidence that there is far more synergy between the computational route and the memory route in lexical processing than cascaded dual route models would suggest.

We therefore consider a slight modification of these symbolic classification models. We consider a model in which two sources of information are used in parallel: the information provided by the form stored in memory (the standard form), and the information provided by analogical gangs. We allow these two sources to be weighted differently. The standard form is the form taught at school and enforced by the orthographic conventions of Dutch. So, we expect that this source of information may have considerably more weight. Hence, our noncascaded model predicts that analogy should favor a nonstandard form with considerable strength before it can actually be selected. Moreover, it predicts that the choice for a nonstandard form should also require more time than a choice that follows the standard. Finally, our model, which takes both the stored forms and the analogical forms into account, predicts that a stronger analogical support for the selected allomorph should result in shorter response latencies. Note that this implies the strong claim that analogical effects should be demonstrable in the response latencies of our experiment even when the participants select the standard allomorph, that is, even when their choice by itself suggests that they have simply retrieved the standard form from memory.

Similar predictions follow from subsymbolic classifiers. When an artifical neural network is trained to map past tense forms onto present tense forms, the weights in the network will assume values that support the standard forms. Gang effects due to patterns of similarities shared by the input and output vectors may arise, but with appropriate parameter settings these gangs can be made to have a relatively weak effect. Consequently, there may be competition between the standard and the nonstandard form, but nonstandard forms will be exceptional. The network will require more cycles to reach a stable state for a nonstandard form, and the stronger the gang's favor for the nonstandard, the more likely a stable state will be reached for the nonstandard form. In addition, the network will also require more cycles to reach a stable state for the standard form if the analogical gang favors the nonstandard.

Since symbolic and subsymbolic classifiers offer similar predictions, we will remain agnostic as to which approach might be preferable. We have opted for using a theory-independent nonparametric classifier to operationalize the notion of analogy. We determined the phonological gangs by means of a classification tree (CART: Breiman et al. 1984; see also 
Clark and Pregibon 1992). The input for the CART analysis was a set of some 1700 monomorphemic stems extracted from the CELEX lexical data base (Baayen et al. 1995). For each stem, the CART tree had to predict the [voice] specification of the final obstruent on the basis of the segments in the final rhyme: the vowel, the prefinal consonant, if present, and the final obstruent. The CART analysis resulted in a cross-validated classification tree that grouped the 1700 stems into eleven sets of words that share similar rhymes and that have a similar preference for a voiced final obstruent. In what follows, we take these sets to be a first approximation of the phonological gangs. The proportion of stems in a gang with final voiced obstruents represents the analogical support (probability) for a final obstruent to be voiced. The gangs are defined in such a way that they not only embrace all existing words, but also nonexisting, and even phonotactically impossible words. They consequently make predictions for existing as well as nonexisting words. In the study of Ernestus and Baayen (2003), the probabilities correlated well with the proportion of participants interpreting the final obstruents of 192 pseudo-words as voiced $\left(r_{s}=0.50, p<0.001\right)$. (This study also discusses more sophisticated theory-dependent formalizations of analogy.)

Table 1 summarizes the analogical gangs of phonologically similar words in terms of the segments of the final rhyme. The segments enclosed by the first pair of brackets represent the vowel, and the segments enclosed by the second pair of brackets the prefinal consonant, with a hyphen indicating the absence of a prefinal consonant. The final pair of

Table 1. Analogical gangs of phonologically similar words defined in terms of the segments of the final rhyme according to a CART analysis of Dutch monomorphemic stems (Ernestus and Baayen 2003)

\begin{tabular}{|c|c|}
\hline Analogical gangs & $\begin{array}{l}\text { Probability } \\
\text { of voicing }\end{array}$ \\
\hline 1. $\{$ ci, au, œy, ai, e:, o:, : i, u $\}\{-, j, 1, \mathrm{~m}, \mathrm{n}, \mathrm{r}\}\{\mathrm{P}\}$ & 0.000 \\
\hline 2. $\{$ ci, au, œy, ai, e: o:, : i, u $\}\{-, j, 1, \mathrm{~m}, \mathrm{n}, \mathrm{r}\}\{\mathrm{T}\}$ & 0.372 \\
\hline 3. $\{\varepsilon i, \mathrm{au}, \propto y$, a: $, \mathrm{e}, \mathrm{o}, \varnothing:, \mathrm{i}, \mathrm{u}\}\{-, \mathrm{j}, 1, \mathrm{~m}, \mathrm{n}, \mathrm{r}\}\{\mathrm{S}\}$ & 0.755 \\
\hline 4. $\{\varepsilon i, a u, œ y, a:, e:, o:,:, i, u, a, \varepsilon, I, \supset, y, y\}\{f, k, p, s, t, x\}\{P, T, S\}$ & 0.019 \\
\hline 5. $\{\mathrm{a}, \varepsilon, \mathrm{I}, \mathrm{\supset}, \mathrm{Y}, \mathrm{y}\}\{-, \mathrm{m}, \mathrm{r}\}\{\mathrm{P}, \mathrm{T}, \mathrm{S}\}$ & 0.135 \\
\hline 6. $\{\mathrm{a}, \varepsilon, \mathrm{I}, \rho, \mathrm{Y}, \mathrm{y}\}\{1, \mathrm{n}\}\{\mathrm{P}, \mathrm{T}, \mathrm{S}\}$ & 0.357 \\
\hline 7. $\{\varepsilon i, a u, a:, e:, o:, \varnothing:, y\}\{-, j, 1, r, m, n\}\{F, X\}$ & 0.992 \\
\hline 8. $\quad\{\mathrm{i}, \mathrm{u}\}\{-, \mathrm{m}\}\{\mathrm{F}\}$ & 0.778 \\
\hline 9. $\{\mathrm{a}, \varepsilon, \mathrm{I}, \mathrm{\rho}, \mathrm{Y}\}\{-, \mathrm{m}\}\{\mathrm{F}\}$ & 0.081 \\
\hline 10. $\{\mathrm{a}, \varepsilon, \mathrm{I}, \supset, \mathrm{y}, \mathrm{i}, \mathrm{u}\}\{1, \mathrm{r}\}\{\mathrm{F}\}$ & 0.775 \\
\hline 11. $\{\mathrm{a}, \varepsilon, \mathrm{I}, \mathrm{\rho}, \mathrm{y}, \mathrm{i}, \mathrm{u}\}\{-\mathrm{j}, \mathrm{l}, \mathrm{r}, \mathrm{m}, \mathrm{n}\}\{\mathrm{X}\}$ & 0.953 \\
\hline
\end{tabular}


brackets encloses the final obstruent. The $\mathrm{P}$ represents bilabial plosives, the $\mathrm{T}$ alveolar plosives, the $\mathrm{S}$ alveolar fricatives, the $\mathrm{F}$ labiodental fricatives, and the $\mathrm{X}$ velar fricatives.

We now turn to our experiment, pitting the predictions of the rulebased account against those of the analogy-based accounts.

\section{Experiment}

\subsection{Participants}

Forty participants, mostly undergraduates at Nijmegen University, were paid to take part in the experiment. All were native speakers of Dutch. At the end of the experiment, they were asked to read aloud the following list of words: lachen /laxən/ 'to laugh,' leger /leyər/ 'army,' richel /rıxəl/ 'ledge,' bogen /boyən/ 'bows,' Pasen / pazən/ 'Easter,' wazig /vazix/ 'hazy,' racen / resən/ 'to race,' vezel /vezəl/ 'fibre,' boffen / bofən/ 'to be lucky,' leven /levən/ 'to live,' puffen /pyfən/ 'to pant,' rover /rovər/ 'robber.' The participants' realizations were taped, and the intervocalic fricatives were transcribed by two native speakers of Dutch as voiced or voiceless. Twenty-four participants realized, according to both transcribers, at least two underlyingly voiced fricatives of different places of articulation as voiced, while realizing all underlyingly voiceless fricatives as voiceless. These participants can probably systematically distinguish between underlyingly voiced and voiceless fricatives. We will refer to these participants as the $[+\mathrm{F}]$ participants. Eleven participants invariably realized all fricatives as voiceless. They appear not to distinguish between underlyingly voiced and voiceless fricatives. These participants are referred to as the $[-\mathrm{F}]$ group. The remaining five participants form an intermediate group $([ \pm \mathrm{F}])$ : they do not distinguish systematically between underlyingly voiced and voiceless fricatives. We excluded participants from Limburg from our experiment, since in several varieties of Dutch spoken in this part of the Netherlands, the past tense forms of all verbs are created with the suffix de.

\subsection{Materials}

We selected all monosyllabic verbs from the CELEX lexical data base (Baayen et al. 1995) that end in an obstruent, have regular past tense forms, and can be combined with the subject pronoun wij 'we.' We discarded the verbs ending in $/ \mathrm{k} /$, since these verbs cannot show analogical 
effects. The obstruent $/ \mathrm{k} /$ has no voiced counterpart, and verbs ending in $/ \mathrm{k} /$ are consequently always followed by te. We also discarded low register, informal words.

The 176 selected verbs, 96 of which have te, and 80 of which have -de as their standard past tense suffix, are listed in the Appendix. In this Appendix, we also listed the frequency of the past tense form of each verb, which we define here as the number of occurrences of the verb stem followed by a past tense suffix in the Dutch part of the CELEX lexical data base. We conflated the frequencies of the singular and plural past tense forms, as these forms tend to be realized identically. The verbs have past tense frequencies between 0 , for the verbs vlaggen 'hang out the flag' and dorsen 'to thresh,' and 68311, for leggen 'to lay.' The verbs end in five different types of final obstruents: 35 verbs end in a bilabial plosive $(\mathrm{P})$, 48 in an alveolar plosive (T), 41 in an alveolar fricative (S), 27 in a labiodental fricative $(\mathrm{F})$, and 25 in a velar fricative $(\mathrm{X})$.

A male speaker of Dutch, who systematically maintains the voiced/ voiceless opposition for all plosives and fricatives, realized the plural present tense forms of the verbs in phrases in which they were preceded by the pronoun wij [vei] 'we.' Examples of these phrases are [vei vrezən] wij vrezen 'we fear,' [vei sxrobən] wij schrobben 'we scrub,' and [vei jœyxən] wij juichen 'we cheer.' The phrases were recorded in a sound attenuated room by means of a DAT-recorder Aiwa HD S100 and a Sony microphone ECM MS957. The recordings were stored as .wav files (sample rate: $48 \mathrm{KHz}$ ) on a computer by means of the speech analysis package Praat (Boersma 1996). They were presented in one of eighteen random orders to the participants with two intervening breaks. These actual test phrases were preceded by nine practice phrases and another break.

\subsection{Procedure}

An experimental trial consisted of a beep $(500 \mathrm{~ms}, 377 \mathrm{~Hz})$ followed by the test phrase over closed headphones (Sony MDR-55). The participants' task was to decide as quickly and as accurately as possible whether the past tense form corresponding to the presented present tense form ends in [tən] $t e+n$ or [dən] $d e+n$. The [n] following the past tense suffixes indicates that the verb form is plural. The participants made their choices known by pressing the ten or den button. Half of the participants pressed the den button with their dominant hand, while the other half pressed the ten button with this hand. The time-out was set to $2500 \mathrm{~ms}$. We presented the phrases auditorily in order to make sure that the par- 
ticipants took the whole word into account, and did not base their choice between ten and den just on the last grapheme of the verb stem. After the participants had pressed a button, they also wrote down the past tense form. These written past tense forms allow us to ascertain whether the participants had understood the presented verbs as intended, and had not understood, for instance, [vei yisən] wij gissen 'we guess' as [vei yistən] wij gisten 'we ferment.' The participants initiated the next trial by pressing the den button.

Since each participant pressed a button as well as wrote down his or her answer for every verb, we have four dependent variables, as already mentioned above. The first one is the suffix writen down by the participant. The second variable represents the inconsistency errors, that is, the inconsistencies between the participants' written choices and the choices they made when pressing a button. The third variable represents the reaction times, and the fourth variable the time-out errors.

\subsection{Results and discussion}

We discarded fourteen trials in which the participants wrote down past tense forms of which the stems do not correspond to the stems of the presented stimuli. For instance, we discarded the trial in which a participant wrote down wij schipten as the past tense form of [vei sximpən] wij schimpen, and the one in which a participant wrote down wij mistten as the past tense form of [vei mIsən] wij missen. The participants probably misunderstood the verbs in these trials. These fourteen trials form less than $0.3 \%$ of all trials. In the analyses of the inconsistency errors and reaction times, we also discarded the 454 trials in which the participants produced time-out errors.

We start the discussion of our results with the analysis of the past tense forms that the participants wrote down. These past tense forms show the participants' final, and therefore, best thought-out choices. For this analysis, we discarded another fourteen trials in which the participants wrote down present tense forms that are homophones with the requested past tense forms. To give an example, we discarded wij boeten as response to [vei butən] wij boeten, which has wij boetten as its correct past tense form. For these trials, we are not certain that the participants responded with a past tense form. We merged all past tense forms of a verb that were written with te and ten. Similarly, we merged the responses written with de and den. The presence or absence of the grapheme $n$ is irrelevant for our research question: as already mentioned above, the grapheme $n$ just in- 
dicates that the number of the verb form is plural. We also merged the forms in which the stems were spelled correctly, and the forms in which the stems were spelled with a grapheme that reflected the wrong underlying [voice]-specification for the final obstruent. For example, we merged krabten and krapten, as responses to [vei krabən] wij krabben. Both forms end in the nonstandard suffix, since the final obstruent of krab is underlyingly voiced $(/ \mathrm{b} /)$, and should therefore be followed by $d e$. The form krabten shows the correct spelling of the verb stem, which equals the underlying form assumed in generative analyses, but it violates the spelling conventions of Dutch, according to which the stem-final grapheme $b$ must be followed by the allomorph de. The form krapten does not show the correct spelling of the verb stem, since the stem-final obstruent is represented as underlyingly voiceless. One might argue that the participants writing down this form did not know that the stem-final obstruent was underlyingly voiced. However, the participants heard [krabən], in which the stem-final obstruent was realized as voiced, and they therefore could deduce from the signal that the stem-final obstruent was underlyingly voiced. We think that the participants wrote down $p$ instead of $b$ simply because $p$ is more in line with the Dutch spelling conventions than $b$ before the allomorph te. We consequently retained in the data set responses such as krapten, in which the spelling of the stem-final obstruent reflects the wrong underlying [voice]-representation. These responses form less than $0.3 \%$ of all responses.

We analyzed the proportion of responses with nonstandard past tense suffixes using a logistic regression analysis. Note that we can only ascertain effects of analogy in the participants' written responses when they report a nonstandard form. When they report a standard form and the phonological gang supports this form, we do not know whether this form has been retrieved from memory or whether it has been computed online. Since analogical models predict that participants should report more nonstandard forms when there is stronger analogical support for the nonstandard suffix, we will gauge the effect of analogy by means of the absolute difference between what the standard prescribes and what is favored by analogy. The standard prescribes de with a probability of either 0 or 1 . The analogical probability with which a verb takes de equals the proportion of words falling in the same phonological gang in Table 1 that end in a voiced obstruent. The absolute difference between these two probabilities will be referred to as the "prediction difference." This variable captures well the competition between standard form and the form supported by the analogical gangs, and we will therefore also use it in the analyses of the three other dependent variables. The verbs in our experiment have prediction differences between 0.000 (e.g. gapen 'to 
yawn' and hopen 'to hope') and 0.992 (e.g. juichen 'to cheer' and doven 'to extinguish').

In addition to prediction difference, we also took into consideration as independent variables the log frequency of the past tense form (conflating the singular and plural past tense frequencies), the type of the stem-final obstruent ( $\mathrm{P}, \mathrm{T}, \mathrm{S}, \mathrm{F}, \mathrm{X})$, the standard suffix (whether the standard prescribes te or de), and participant group $([+\mathrm{F}],[-\mathrm{F}]$, and $[ \pm \mathrm{F}])$.

A logistic regression analysis revealed significant main effects for all variables (prediction difference: $\mathrm{F}(1,526)=154.83, \mathrm{p}<0.001$; $\log$ frequency of the past tense form: $\mathrm{F}(1,524)=66.30, \mathrm{p}<0.001$; the type of the stem-final obstruent: $\mathrm{F}(4,521)=84.69, \mathrm{p}<0.001$; the standard suffix: $\mathrm{F}(1,520)=19.46, \mathrm{p}<0.001$; and participant group; $\mathrm{F}(2,518)=9.71$, $\mathrm{p}<0.001)$. Participants created more nonstandard past tense forms for verbs with higher prediction differences, for verbs with lower-frequency past tense forms, for verbs with stems ending in alveolar or labiodental fricatives, and for verbs for which the standard prescribes de. The participants of the $[ \pm F]$ group, who unsystematically distinguish between voiced and voiceless fricatives, created more violations than the other participants. Given the small number of participants in this group (five), this main effect of group may not be reliable. Due to singularity in the data matrix, no interactions could be incorporated in the model.

The logistic regression model should be interpreted with caution, however, since the residuals of the model show considerable deviations from normality. We therefore also analyzed the proportion of nonstandard past tense forms by means of a (nonparametric) classification and regression tree (CART) analysis (Breiman et al. 1984), with mincut set to 10 . The resulting cross-validated pruned tree is shown in Figure 1. The higher a partition is up in the tree, the more relevant it is. In addition, the vertical length of the branches reflects the relevance of the factors, that is, the explained "variance" (technically, the reduction in node heterogeneity). The figure shows that the first branch or partition in the tree is based on the prediction difference. Further branches show that the type of the stem-final obstruent and the frequency of the past tense form are relevant. The type of obstruent is relevant in case the prediction difference is low: larger numbers of nonstandard forms are found in the case of stem-final alveolar fricatives and stem-final labiodental fricatives. When the prediction difference is high, the frequency of the past tense forms of the verbs emerges as relevant: the lower the frequency of the past tense form of a verb is, the more nonstandard past tense formations are reported. The regression tree presents no evidence for an effect of the standard suffix, nor for an effect of participant group. In conclusion, this analysis presents roughly the same picture as the logistic regression model. 


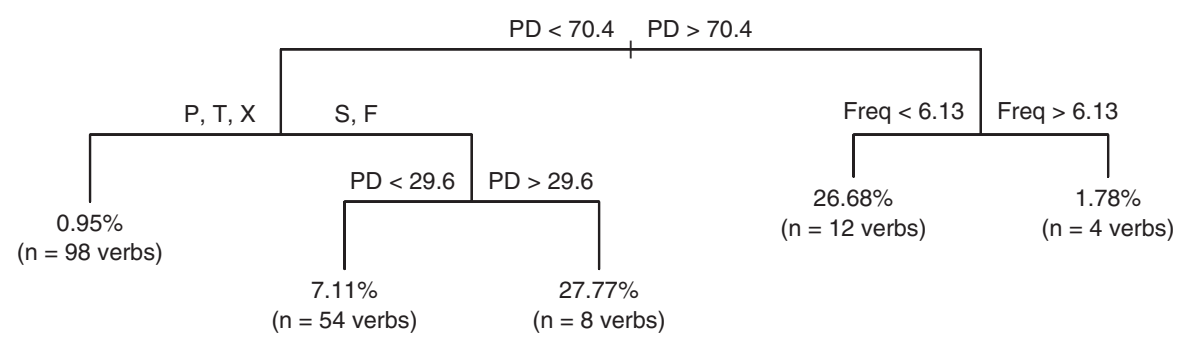

Figure 1. CART analysis of percentages of written violations of the rule (PD: prediction difference; Freq: $\log$ [frequency +1$]$ )

The main effect of prediction difference challenges the rule-based account. This account predicts no systematic effect of analogical gangs on the choices made by the participants, contrary to fact. In addition, the absence of a reliable effect for participant group provides further evidence against the rule-based account. Under the rule-based account, one would expect that the $[-\mathrm{F}]$ participants, who do not realize the difference between voiced and voiceless fricatives in their own speech, would show the largest effects of analogy. However, all participant groups emerge as very similar with respect to the effects of analogy. The effect of frequency is as expected: When the frequency of the standard form is low, the form supported by the phonological gangs meets less resistance from the standard form. The effect of the type of the final obstruent shows that participants produced more nonstandard forms for words ending in alveolar and labiodental fricatives than for words ending in plosives or velar fricatives. This may stem from the Dutch spelling conventions, which prescribe that alveolar and labiodental fricatives are always spelled as voiceless before both te and $d e$. This convention implies that the orthographic forms of stems ending in alveolar or labiodental fricatives do not provide any information about the past tense allomorph required by the standard conventions. In the absence of this information, more nonstandard forms are to be expected. Finally, the participants created more nonstandard forms for verbs of which the standard past tense forms end in $d e$. This suggests that participants had a preference for te. There are two possible explanations for this preference. The first explanation is that most verbs ending in an obstruent take te in the standard forms, and the experiment, correspondingly, contains more verbs taking te $(54 \%)$ than verbs taking de $(46 \%)$. The participants had to press the ten button more often, and this may have induced a list effect favoring te. A second explanation builds on the observation that word-internal obstruent clusters in Dutch tend to be voiceless in monomorphemic words (Zonneveld 1993). Speakers may 
generalize this regularity to morphologically complex words. They would then show a preference for $t e$ because obstruents followed by te create voiceless obstruent clusters, that is, obstruent clusters of the unmarked type.

We now turn to the 152 inconsistency errors, that is, the trials in which the participants pressed the ten button but wrote down den, or vice versa. A logistic regression model showed main effects for all variables (prediction difference: $\mathrm{F}(1,526)=18.63, \mathrm{p}<0.001$; log frequency of the past tense form: $\mathrm{F}(1,524)=6.43, \mathrm{p}=0.01$; type of the final obstruent: $\mathrm{F}(4,521)=20.75, \mathrm{p}<0.001$; standard suffix: $\mathrm{F}(1,520)=10.14$, $\mathrm{p}=0.001$; and participant group: $\mathrm{F}(2,518)=4.87, \mathrm{p}=0.008)$. The participants created more inconsistency errors for verbs with higher prediction differences, for verbs with lower-frequency past tense forms, for verbs with stems ending in alveolar or labiodental fricatives, and for verbs for which the standard prescribes the suffix $d e$. The model also revealed an interaction of the type of the stem-final obstruent by the standard suffix $(F(4,513)=10.20, p=0.04)$. The participants with a systematic distinction between underlyingly voiced and voiceless fricatives $([+\mathrm{F}])$ were the least consistent. However, this effect of participant group may be due to the small number of participants in the $[ \pm F]$ group $(=5)$. Removal of these five participants from the data set resulted in a model in which participant group is not significant $(p>0.1)$.

Unfortunately, the residuals of this logistic model are again not normally distributed, which implies that the model should be interpreted with caution. A CART analysis of the data indicates that the type of the stemfinal obstruent and the prediction difference are good predictors of the proportions of inconsistency errors. The pruned cross-validated classification tree is shown in Figure 2. Verbs ending in alveolar or labiodental fricatives (right-hand branch of the tree) tend to cause more inconsistency errors than verbs ending in plosives or in velar fricatives (left-hand branch of the tree). In addition, verbs with a higher prediction difference cause more inconsistency errors than verbs with a lower prediction difference. The frequency of the past tense form is a predictor as well, but only for a small subset of the data: verbs ending in a plosive or a velar fricative that have a high prediction difference cause more inconsistency errors if their past tense form is of a low frequency of occurrence $(8.43 \%)$ than if it is of a high frequency $(2.36 \%)$.

These analyses of the inconsistency errors support the conclusions reached on the basis of the proportions of nonstandard forms.

We analyzed the reaction times for the trials leading to standard and nonstandard forms jointly by means of Linear Mixed Effects (LME) models (Pinheiro and Bates 2000; Baayen, Tweedie, and Schreuder 2002). An LME analysis of all these trials with log reaction time as dependent 


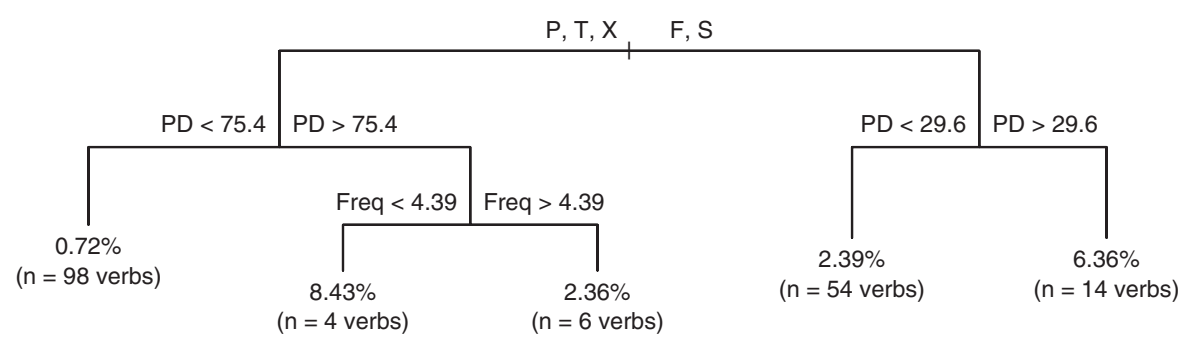

Figure 2. CART analysis of the percentages of inconsistency errors (PD: prediction difference; Freq: $\log$ [frequency +1$]$ )

variable revealed main effects for prediction difference $(F(1,6722)=$ $39.20, p<0.0001)$, frequency $(F(1,6722)=180.13, p<0.0001)$, type of final obstruent $(F(4,6722)=14.71, \quad p<0.0001)$, standard suffix $(F(1,6722)=89.84, p<0.0001)$, and interactions of type of obstruent by prediction difference $(F(4,6722)=4.71, p=0.0009)$, and of type of obstruent by standard suffix $(F(4,6722)=3.63, p=0.0059)$. Participant group was not a significant predictor. The residuals of the model are normally distributed.

The random effects part of the LME model shows that there are individual differences between the participants with respect to their sensitivity to frequency and to type of obstruent (log-likelihood ratio $=138.41$, $p<0.0001)$. These differences are probably due to the differences in the individual mental lexicons of the participants: the participants do not know exactly the same words, and moreover, have encountered the words that they do know different numbers of times. The phonological gangs and the strengths of the standard forms consequently vary somewhat across participants. The residual standard deviation of the model was 0.492 .

In the LME regression model, the prediction difference has a significant and positive coefficient. This is exactly as predicted by an analogical account. If the prediction difference is larger, the analogy more strongly supports the nonstandard suffix. Consequently, the competition between the standard and nonstandard suffix is larger, leading to longer reaction times. Vice versa, if the prediction difference is smaller, the analogy more strongly supports the standard suffix, and the reaction times are shorter. The analogical sets listed in Table 1 clearly show gang effects.

Not surprisingly, the main effect of frequency is facilitatory. Present tense forms with higher frequencies are recognized faster than low frequency verb forms (Baayen et al. 2003). In addition, participants can start producing a past tense form faster when the form is of a high 
frequency than when it is of a low frequency of occurrence (Oldfield and Wingfield 1965; Jescheniak and Levelt 1994).

The main effect of the standard suffix shows that participants respond faster when they opt for the past tense suffix te. This effect in the response latencies corresponds with the preference for te observed in the logistic regression analysis of the counts of nonstandard responses and inconsistency errors. Note that the fast reaction times for te cannot be due to the positions of the buttons with respect to the participants' dominant hands, since half of the participants pressed the ten button with their dominant hand, while the other half pressed the den button with this hand. (The position of the buttons with respect to the dominant hand did not emerge as significant when added to the LME model.)

The main effect of type of obstruent may in part be due to the orthographic conventions of Dutch, which, as explained above, differ for labiodental and alveolar fricatives compared to the other obstruents. We are uncertain about how to interpret the interaction of the type of obstruent by prediction difference. We suspect that prediction difference, as defined in terms of CART-derived probabilities, may not be sensitive enough to capture the full contributions of the different types of obstruents.

We also analyzed separately the trials leading to standard forms and the trials leading to nonstandard forms. The analysis of the trials leading to standard forms show exactly the same main effects and the same interactions as the main analysis. The analysis of the trials leading to nonstandard forms shows a main effect of the standard suffix $(F(1,120)=$ $3.968, p=0.0486$ ), and an interaction of frequency by type of final obstruent $(F(4,120)=3.927, p=0.0050)$. There are no main effects of prediction difference, frequency, and type of final obstruent, probably because most verbs leading to nonstandard forms are of a high prediction difference, of a low frequency of occurrence, and end in alveolar or labiodental fricatives (see the analysis of the nonstandard forms above). The interaction of frequency by type of final obstruent shows that frequency remains relevant also for these words.

These results from the LME analysis again argue against the rule-based account. The main effect of prediction difference shows that the effect of phonological gangs is pervasive, instead of being restricted to occasional, random lapses in performance. It shows competition between the standard and nonstandard forms, and it, therefore, indicates, furthermore, that memory-retrieval and analogical computation are not simply cascaded but operate in parallel.

Finally, we discuss the 454 time-out errors. We first analyzed the data with a stepwise logistic regression model, which revealed main effects for 


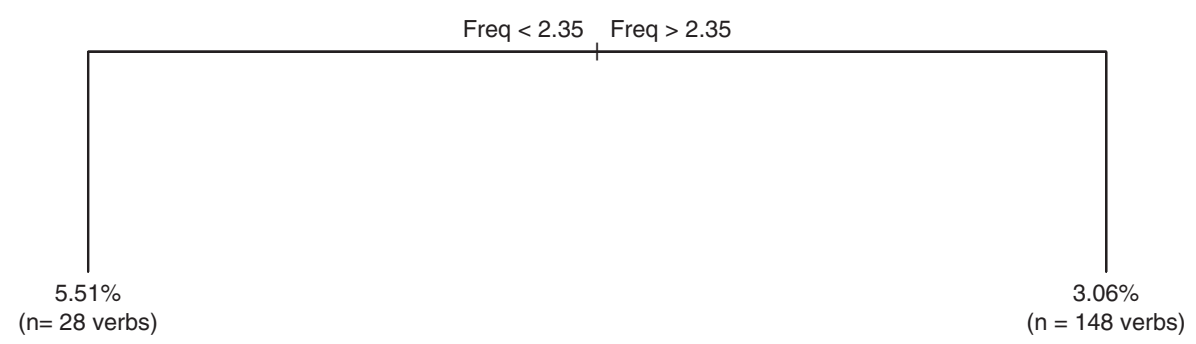

Figure 3. CART analysis of the percentages of time out errors (PD: prediction difference; Freq: $\log [$ [frequency +1$]$ )

frequency $(F(1,526)=19.27, p<0.0001)$ and standard suffix $(F(1,525)$ $=6.07, p<0.0137)$, as well as an interaction of standard suffix by prediction difference $(F(2,523)=4.94, p=0.0072)$. A higher frequency led to fewer time-out errors, and when the standard prescribes te, participants made fewer time-out errors than when the standard prescribes de. The interaction of standard by prediction difference also documents the previously observed preference for $t e$ : when the standard prescribes $t e$, while the phonological gangs support de, participants produce more time-out errors than in the reverse situation. The residuals of this logistic models are again not normally distributed, and we also analyzed the time-out errors with a CART analysis. This analysis revealed only an effect for frequency (see Figure 3).

\section{General discussion}

This study addresses the question to what extent the production of regular past tense forms in Dutch is affected by analogical processes. Standard generative analyses view the suffixation of $d e$ or te to the verb stem as a completely regular process governed by the underlying [voice]specification of the stem-final obstruent. We have pitted this rule-based account against an analogical account according to which the phonological similarity structure of the words in the lexicon affects the choice of the past tense allomorph. The experiment reported in the present study shows that analogical similarity indeed affects past tense production across the board, even when participants produce standard forms, while having all relevant information to apply the rule at their disposal.

In our experiment, we presented plural present tense forms to participants over headphones, and asked them to produce the corresponding past tense forms. In Dutch, past tense forms are created by adding the suffix $t e(n)$ or $d e(n)$ to the verb stems. The participants' task was to press as quickly and as accurately as possible the ten or den button, and sub- 
sequently write down the whole past tense form. The experiment yielded four dependent variables: (1) the proportion of nonstandard past tense forms written down by the participants, (2) the inconsistency errors between the suffixes that the participants chose when pressing a button and the suffixes in the past tense forms they wrote down, (3) the reaction times, and (4) the time-out errors.

We found that three dependent variables show a main effect of analogy: participants created more nonstandard past tense forms, produced more inconsistency errors, and reacted more slowly for verbs with stronger analogical support for the nonstandard allomorph.

These findings are problematic for the classic rule-based account for the following reasons. First, the rule-based account predicts that the analogical support for a nonstandard allomorph should not affect normal past tense production, contrary to fact. Second, under the rule-based account, one might expect that participants who do not produce a systematic difference between voiced and voiceless fricatives in their own speech might be more prone to fall back on analogical reasoning. However, there is no evidence in our data that this might be the case. Third, classic rule-based accounts stagger rule-based processes and analogical fall-back procedures. In the framework of Anshen and Aronoff (1988), analogical processes are described as slow compared to rule-based processes, and rules should determine the outcome without interference from analogical processes. No competition is expected between the standard and nonstandard allomorph, contrary to fact. In the dual route model of Pinker (1999), production proceeds by first attempting lexical look-up in an associative memory (where similarity effects might arise). Upon failure of this look-up, which is the normal situation for regular inflected forms, a symbolic rule is assumed to be started up. Again, this is an account that does not predict the observed competition between the standard and nonstandard allomorphs.

One might argue that the present results are artificial and induced by the task. Although we cannot prove that this is not the case, we can point out that nonstandard forms are not exceptional in Dutch. The transcription of 100 past tense forms from the "Corpus of Spoken Dutch" (CGN: Corpus Gesproken Nederlands, http://www.elis.rug.ac.be/cgn/index_nl. html) with strong analogical support for the nonstandard suffix (prediction difference $>0.5$ ) yielded, according to seven transcribers, at least four nonstandard past tense forms: eisde 'demanded' (r3nl_24/fn001389), deinste 'winced' (r3nl_20/fn001151), bonste 'banged' (r3nl_20/fn001175), and vergisde 'was mistaken' ( $\left.\mathrm{r} 3 \mathrm{nl} \_19 / \mathrm{fn} 001080\right)$. This simple survey shows that nonstandard forms are not uncommon and that they are not restricted to written language. 
We conclude that the traditional rule-based account cannot provide an insightful explanation of our data. However, there are several other theoretical frameworks that can incorporate these results. Stochastic Optimality Theory ([Boersma 1998] henceforth SOT) is a linguistic framework in which probabilistic data can be handled (see, e.g., Manning 2003 for a comparison of SOT with standard statistical approaches). In SOT, the phonological gangs as captured by CART can be reconceptualized and mapped onto probabilistic violable constraints. Ernestus and Baayen (2003) show how SOT can be used to model the choice of the past tense allomorphs for pseudo-verbs. In order to account for the production of past tense forms of existing verbs, the competition between the standard form and the nonstandard, as moderated by the similarity structure in the lexicon, has to be incorporated. This can probably be done by adding faithfulness constraints that demand faithfulness of the output with respect to the stored standard past tense form. Given the observed effect of word frequency, the position of these faithfulness constraints in the constraint hierarchy should be made dependent on the frequency of the relevant individual past tense forms. We do not see, however, how SOT might account for the inhibitory effect of the competition between the standard and nonstandard forms on the reaction times.

Another linguistic framework in which the present data can be accounted for is the analogical approach exemplified by TiMBL and AML. These analogical models are very good at capturing the analogical support of phonological gangs for nonstandard forms. However, the competition between the standard and nonstandard form attested in our experimental data is not expected by these models as currently formulated. In TiMBL, if the standard form is in the lexicon, it will be retrieved and no analogical computations will take place. In AML, the presence of the standard form in the lexicon blocks the analogical force of the phonological gangs. AML does incorporate the possibility of imperfect memory (Skousen 1989), that is, standard forms may sometimes not be accessible, in which case analogical effects will emerge. However, even with imperfect memory, there is no competition between the standard and nonstandard forms. Both TiMBL and AML can easily be modified such that two (potentially conflicting) sources of evidence are taken into account: the frequency-weighted evidence stemming from the standard form, and the evidence residing in the similarity structure among the other forms in the lexicon.

Finally, the present data pose no problem for connectionist models either. In particular, the competition between the standard and nonstandard alternatives follows naturally in this framework as the result of exposure to the standard form in combination with gang effects emerging as 
a consequence of partial similarities in the mapping between present and past tense forms.

Various researchers have argued that language is inherently graded, nondeterministic, and probabilistic (e.g. Bybee 1985, 2001; Skousen 1989, 1993; Daelemans et al. 1994; Daelemans et al. 1995; Rumelhart and McClelland 1986; Plunkett and Juola 1999; Sandra et al. 1999; Eddington 2000; Plaut and Gonnerman 2000; Seidenberg and Gonnerman 2000; Ramscar 2002). The present data provide further evidence that this view is correct.

Received 7 January 2003

Revised version received

10 April 2003
Catholic University Nijmegen Max Planck Institute for Psycholinguistics,

\section{Appendix}

Material used in the experiment. Each word is followed by the logarithm of the frequency of its past tense form +1 (conflating the singular and plural forms); its prediction difference; the proportions of nonstandard forms produced in Group I (participants with a systematic distinction between underlyingly voiced and voiceless fricatives), Group II (participants without such a distinction), and Group III (intermediate participants); the proportions of inconsistency errors in Groups I, II, and III; the mean reaction times in ms for Groups I, II, and III; and the proportion of time-out errors for Groups I, II, and III.

Verbs prescribed to be suffixed with te:

blaffen 'to bark' 5.560 .09100 .000 .000 .200 .040 .000 .006816285180 .040 .00 0.40 ;

blaten 'to bleat' 2.200 .37200 .000 .000 .200 .000 .000 .007087788720 .040 .00 0.20 ;

blussen 'to extinguish' 2.56 0.1350 0.000 .000 .000 .000 .000 .007358377640 .00 0.000 .00 ;

boeten 'to suffer' 1.950 .37200 .000 .000 .000 .000 .000 .007046948480 .080 .00 0.00 ;

dansen 'to dance' 6.770 .35700 .120 .180 .200 .100 .090 .208086004210 .120 .00 0.00

dopen 'to sop' 4.710 .00000 .000 .090 .000 .000 .090 .008491169760 .000 .00 0.00 ;

doppen 'to shell' 2.080 .13500 .000 .180 .000 .000 .000 .008389648270 .080 .00 0.00 ;

dorsen 'to thresh' 0.000 .13500 .000 .180 .200 .000 .100 .0011489738850 .080 .09 0.00 ; 
eisen 'to require' 6.580 .76500 .080 .090 .000 .080 .000 .008539888660 .000 .18 0.00 ;

fronsen 'to frown' 5.950 .35700 .500 .820 .600 .130 .000 .209275927170 .040 .00 0.00 ;

gapen 'to yawn' 5.090 .00000 .080 .090 .000 .000 .000 .007657767690 .000 .00 0.00 ;

gissen 'to guess' 2.400 .13500 .000 .000 .000 .080 .000 .0086153412150 .000 .20 0.00

glippen 'to slip' 5.330 .13500 .000 .000 .000 .040 .090 .00736106110550 .040 .00 0.00 ;

grissen 'to snatch' 4.980 .13500 .000 .000 .000 .000 .000 .0082562412240 .080 .09 0.00 ;

groeten 'to greet' 6.150 .37200 .000 .000 .000 .000 .000 .006996144860 .000 .00 0.00

happen 'to bite' $4.96 \quad 0.1350 \quad 0.00 \quad 0.00 \quad 0.00 \quad 0.00 \quad 0.00 \quad 0.00759836810 .000 .00$ 0.00 ;

haten 'to hate' 6.350 .37200 .000 .000 .000 .000 .000 .006056667680 .000 .000 .00 ; heersen 'to rule' $0.00 \quad 0.76500 .040 .180 .200 .100 .100 .008116137940 .090 .09$ 0.00 ;

heten 'to be called' 7.770 .37200 .000 .000 .000 .000 .000 .006054495320 .000 .09 0.00 ;

hopen 'to hope' 7.370 .00000 .040 .000 .000 .040 .090 .0072992310240 .000 .00 0.00

juichen 'to cheer' 5.300 .99200 .210 .360 .750 .090 .000 .006048248080 .080 .00 0.25 ;

kapen 'to hijack' $2.300 .0000 \quad 0.00 \quad 0.00 \quad 0.00 \quad 0.00 \quad 0.00 \quad 0.007247777790 .000 .00$ 0.20

klampen 'to cling' 5.250 .13500 .000 .000 .000 .000 .000 .008596558990 .000 .00 0.00 ;

klappen 'to clap' 6.220 .13500 .000 .000 .000 .000 .000 .006385896550 .040 .00 0.00

klitten 'to get entangled' $2.40 \quad 0.1350 \quad 0.00 \quad 0.00 \quad 0.00 \quad 0.00 \quad 0.00714539841 \quad 0.08$ 0.000 .00

kloppen 'to knock' 7.300 .13500 .000 .000 .000 .000 .000 .006436865610 .000 .00 0.00 ;

knappen 'to crack' 4.690 .13500 .000 .000 .000 .000 .000 .007228137870 .040 .00 0.00

knarsen 'to crunch' 4.620 .13500 .000 .180 .000 .000 .000 .006817627820 .000 .00 0.00 ;

knippen 'to cut' 6.110 .13500 .000 .000 .000 .000 .000 .006577317960 .040 .00 0.00 ;

knopen 'to knot' $5.830 .0000 \quad 0.000 .000 .000 .000 .090 .00652649030 .000 .00$ 0.00

krassen 'to scratch' 4.750 .13500 .000 .000 .000 .000 .090 .006935665270 .040 .00 0.00 ; 
krijsen 'to screech' 5.270 .76500 .120 .000 .200 .050 .000 .007387478650 .080 .09 0.20 ;

kruisen 'to cross' 5.500 .76500 .080 .180 .200 .120 .000 .0071965910980 .000 .00 0.00 ;

kuchen 'to cough' 5.290 .95300 .040 .000 .000 .000 .100 .0072496412560 .000 .00 0.00 ;

kussen 'to kiss' $7.220 .1350 \quad 0.00 \quad 0.000 .200 .00 \quad 0.000 .255237646020 .040 .09$ 0.20 ;

lachen 'to laugh' $8.640 .95300 .040 .000 .00 \quad 0.000 .00 \quad 0.006068453840 .000 .09$ 0.20 ;

lassen 'to weld' 2.480 .13500 .040 .090 .200 .040 .000 .007316929130 .040 .09 0.00

letten 'to pay attention' 6.590 .13500 .000 .000 .000 .000 .000 .007125285990 .04 0.090 .00 ;

loensen 'to squint' 2.080 .76500 .540 .550 .600 .050 .000 .2010559429990 .120 .18 0.00 ;

lossen 'to discharge' 5.390 .13500 .080 .000 .400 .040 .000 .00688813880 .040 .20 0.00 ;

loten 'to draw lots' 0.690 .37200 .000 .000 .000 .000 .000 .008576038490 .080 .00 0.00 ;

missen 'to miss' 6.650 .13500 .000 .000 .000 .000 .000 .006116955060 .000 .00 0.00

motten 'to have to' $4.900 .13500 .000 .00 \quad 0.000 .000 .000 .00112898511980 .04$ 0.180 .00 ;

passen 'to fit' 7.080 .13500 .000 .000 .200 .000 .000 .007327276040 .000 .09 0.00; persen 'to press' 5.300 .13500 .000 .090 .000 .040 .090 .006327849870 .000 .00 0.00 ;

piepen 'to squeak' 5.040 .00000 .000 .000 .000 .040 .000 .00685526960 .000 .00 0.00 ;

planten 'to plant' 5.090 .35700 .000 .000 .000 .000 .000 .005485467120 .000 .00 0.00 ;

pleiten 'to plead' 5.360 .37200 .000 .000 .000 .000 .000 .007145726210 .000 .00 0.00 ;

ploffen 'to thud' 4.820 .09100 .080 .090 .400 .080 .090 .2571371311680 .000 .00 0.20 ;

pochen 'to boast' 3.430 .95300 .040 .000 .200 .040 .000 .258047959230 .000 .00 0.20 ;

poepen 'to shit' 2.640 .00000 .040 .000 .000 .000 .000 .0085574912680 .040 .00 0.00 ;

poffen 'to roast' 1.100 .09100 .000 .090 .400 .000 .090 .007819108810 .040 .00 0.00 ;

praten 'to talk' $7.57 \quad 0.37200 .00 \quad 0.00 \quad 0.00 \quad 0.050 .00 \quad 0.00486349417 \quad 0.080 .09$ 0.20

putten 'to draw' $5.530 .13500 .000 .000 .00 \quad 0.040 .000 .005516756530 .000 .00$ 0.00 ; 
rapen 'to pick up' $0.00 \quad 0.0567 \quad 0.00 \quad 0.00 \quad 0.00 \quad 0.00 \quad 0.04 \quad 0.1008416258620 .00$ 0.090 .00

reppen 'to scurry' 4.620 .13500 .000 .000 .000 .000 .000 .0083299913320 .000 .00 0.00 ;

schatten 'to estimate' $5.960 .1350 \quad 0.00 \quad 0.00 \quad 0.00 \quad 0.00 \quad 0.00 \quad 0.00628547290 .04$ 0.090 .00

scheppen 'to create' $5.340 .1350 \quad 0.00 \quad 0.00 \quad 0.00 \quad 0.00 \quad 0.00 \quad 0.007617426340 .00$ 0.000 .00 ;

schimpen 'to scoff' 2.640 .13500 .000 .000 .000 .000 .000 .008689351220 .090 .00 0.00

schoppen 'to kick' 5.990 .13500 .000 .000 .000 .000 .000 .006017726370 .000 .09 0.00 ;

schorsen 'to suspend' 2.40 $0.1350 \quad 0.000 .090 .000 .050 .000 .008806647980 .00$ 0.090 .00 ;

schrapen 'to scrape' $5.850 .0000 \quad 0.00 \quad 0.00 \quad 0.00 \quad 0.00 \quad 0.00 \quad 0.006476919210 .00$ 0.000 .20

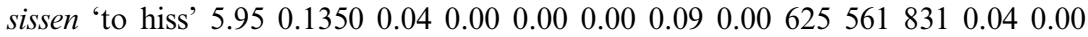
0.00

slepen 'to drag' 6.310 .00000 .000 .000 .200 .000 .000 .00567491640 .000 .000 .00 ;

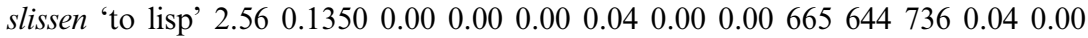
0.20 ;

sloffen 'to shuffle' 4.720 .09100 .000 .000 .000 .040 .000 .007057748660 .040 .00 0.00 ;

slorpen 'to slurp' $1.610 .1350 \quad 0.000 .00 \quad 0.200 .00 \quad 0.00 \quad 0.001211116314860 .08$ 0.090 .20 ;

snappen 'understand' $5.160 .13500 .00 \quad 0.000 .00 \quad 0.000 .00 \quad 0.006885496390 .00$ 0.000 .00

spatten 'to splash' 5.380 .13500 .000 .000 .000 .000 .000 .006566577540 .000 .00 0.20 ;

spotten 'to mock' 5.100 .13500 .000 .000 .000 .000 .000 .005715277660 .040 .00 0.00

stampen 'to stamp' 5.320 .13500 .000 .000 .000 .000 .000 .008379439280 .000 .18 0.00

stappen 'to step' 8.100 .13500 .000 .000 .000 .000 .000 .0076553610630 .000 .00 0.20

starten 'to start' $5.760 .1350 \quad 0.000 .00 \quad 0.00 \quad 0.000 .00 \quad 0.008476586380 .040 .00$ 0.00

steppen 'to ride a scooter' $1.100 .1350 \quad 0.00 \quad 0.00 \quad 0.00 \quad 0.00 \quad 0.00 \quad 0.00723804839$ 0.000 .000 .00 ;

stoppen 'to stop' $7.590 .1350 \quad 0.00 \quad 0.000 .000 .00 \quad 0.00 \quad 0.00704601610 .000 .00$ 0.00

storten 'to crash' $6.530 .13500 .000 .00 \quad 0.000 .000 .000 .005454277940 .000 .00$ 0.00

stoten 'to thrust' 6.780 .37200 .000 .000 .000 .000 .000 .005217233930 .000 .09 0.00 ; 
stuiten 'to be stopped' 5.640 .37200 .000 .000 .000 .000 .000 .0064543610440 .04 0.000 .00 ;

stunten 'to stunt' 0.000 .35700 .000 .000 .000 .000 .000 .007166347610 .120 .000 .00 ; stutten 'to prop' 1.790 .13500 .000 .000 .000 .000 .000 .006345568360 .040 .00 0.00 ;

suffen 'to doze' 1.950 .09100 .040 .090 .400 .000 .000 .009549679780 .000 .00 0.00 ;

surfen 'to surf' $0.00 \quad 0.8750 \quad 0.250 .360 .200 .100 .090 .0093388410060 .120 .00$ 0.00 ;

trappen 'to kick' $6.13 \quad 0.1350 \quad 0.000 .000 .000 .040 .000 .006336024650 .000 .00$ 0.00

uiten 'to utter' 5.770 .37200 .000 .000 .000 .000 .000 .006524968550 .040 .090 .00 ; vatten 'to grasp' $6.440 .13500 .00 \quad 0.00 \quad 0.00 \quad 0.00 \quad 0.000 .00674654530 .000 .00$ 0.00 ;

venten 'to hawk' $1.950 .35700 .000 .000 .00 \quad 0.000 .000 .007737997840 .000 .00$ 0.00 ;

vissen 'to fish' 5.130 .13500 .040 .000 .000 .000 .000 .006998388010 .000 .090 .00 ; vitten 'to carp' $2.480 .1350 \quad 0.00 \quad 0.00 \quad 0.00 \quad 0.00 \quad 0.00 \quad 0.006616958260 .04 \quad 0.00$ 0.00 ;

vorsen 'to research' 1.610 .13500 .040 .090 .400 .050 .100 .00101110869050 .04 0.090 .00

walsen 'to waltz' 2.560 .35700 .290 .550 .600 .080 .000 .009659057360 .000 .09 0.00 ;

wassen 'to wash' 5.770 .13500 .000 .000 .200 .000 .000 .006797397120 .000 .00 0.00 ;

wensen 'to wish' 7.200 .35700 .080 .090 .400 .040 .090 .2079281713830 .000 .00 0.00

wippen 'to hop' 5.570 .13500 .000 .000 .000 .000 .000 .0067792710050 .040 .00 0.00 ;

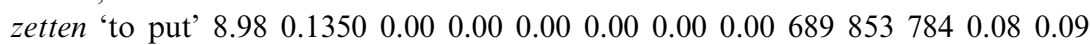
0.00 ;

zweten 'to sweat' 5.010 .37200 .000 .000 .000 .000 .000 .006756119960 .000 .00 0.00

zwiepen 'to bounce' $4.610 .0000 \quad 0.00 \quad 0.090 .00 \quad 0.00 \quad 0.00 \quad 0.007547327310 .08$ 0.000 .00 .

Verbs prescribed to be suffixed with de:

beven 'to shake' 6.080 .00800 .000 .000 .200 .040 .000 .0090010028040 .040 .00 0.00 ;

blieven 'to like' 2.080 .22200 .120 .550 .200 .050 .000 .00115811912370 .170 .09 0.00 ;

blozen 'to bloom' 5.670 .23500 .040 .180 .000 .090 .090 .009878967540 .040 .00 0.00 ;

bonzen 'to bang' 5.450 .64300 .120 .180 .200 .130 .000 .0083974210610 .040 .00 0.00 ; 
braden 'to roast' $2.770 .62800 .000 .00 \quad 0.000 .000 .000 .007837419200 .040 .00$ 0.00

branden 'to fire' 6.840 .64300 .000 .000 .000 .040 .000 .005414836100 .040 .09 0.00 ;

deinzen 'to wince' 5.300 .23500 .040 .180 .000 .040 .000 .008738096640 .040 .18 0.00 ;

deugen 'to be good' $4.830 .00800 .000 .00 \quad 0.00 \quad 0.00 \quad 0.00 \quad 0.006387126200 .04$ 0.000 .00 ;

doven 'to extinghuish' 5.370 .00800 .080 .000 .200 .000 .000 .0070690111120 .04 0.000 .00

draven 'to trot' 5.090 .00800 .000 .090 .000 .000 .000 .008478737840 .000 .000 .00 ; dreigen 'to threaten' $6.940 .00800 .00 \quad 0.00 \quad 0.00 \quad 0.00 \quad 0.00 \quad 0.006936697360 .00$ 0.000 .00 ;

drogen 'to dry' $5.320 .00800 .00 \quad 0.00 \quad 0.00 \quad 0.000 .00 \quad 0.007248359930 .040 .00$ 0.00

dubben 'to waver' 1.100 .86500 .290 .450 .400 .140 .090 .001108114613990 .12 0.000 .20 ;

duiden 'to point' 4.920 .62800 .000 .000 .000 .000 .090 .007677214320 .000 .00 0.20 ;

dulden 'to endure' 4.930 .64300 .000 .000 .000 .000 .000 .006524586450 .000 .00 0.40 ;

durven 'to dare' 7.750 .12500 .000 .090 .000 .000 .180 .008046688180 .040 .00 0.00

glanzen 'to gleam' 5.900 .64300 .080 .090 .000 .090 .000 .006965438690 .040 .00 0.00 ;

grenzen 'to border' 4.820 .64300 .000 .180 .200 .050 .110 .008871069400 .080 .18 0.00

grijnzen 'to grin' $6.73 \quad 0.2350 \quad 0.120 .000 .200 .040 .000 .007409188430 .040 .00$ 0.20 ;

hijgen 'to pant' $6.08 \quad 0.00800 .040 .090 .200 .130 .000 .0084977712260 .040 .00$ 0.20

hoeven 'to need to' 7.880 .22200 .040 .180 .000 .000 .000 .008719618830 .040 .00 0.00 ;

klagen 'to complain' $6.03 \quad 0.00800 .000 .000 .00 \quad 0.00 \quad 0.000 .006025986110 .00$ 0.000 .00

kleden 'to dress' 6.300 .62800 .000 .000 .000 .000 .090 .008038627910 .090 .00 0.00 ;

kleven 'to stick' $5.370 .00800 .040 .090 .00 \quad 0.000 .090 .008367127750 .040 .00$ 0.00

kneden 'to knead' 4.290 .62800 .000 .000 .000 .000 .000 .007866077710 .090 .00 0.00 ;

krabben 'to scratch' 5.680 .86500 .580 .180 .600 .140 .090 .00959108112530 .12 0.000 .00

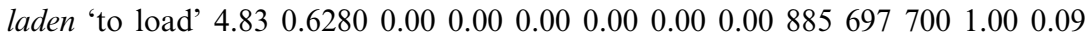
0.00 ; 
landen 'to land' $5.380 .64300 .000 .000 .00 \quad 0.000 .000 .006864835840 .040 .00$ 0.00 ;

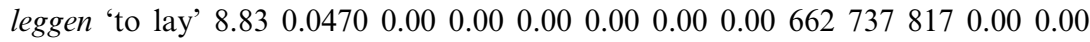
0.00

leiden 'to lead' $7.890 .62800 .000 .000 .00 \quad 0.000 .00 \quad 0.0079975411090 .040 .00$ 0.20 ;

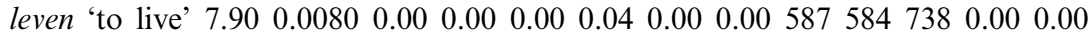
0.00 ;

loven 'to praise' $3.530 .00800 .00 \quad 0.000 .00 \quad 0.000 .00 \quad 0.008116628130 .080 .09$ 0.00 ;

lozen 'to drain' $3.04 \quad 0.2350 \quad 0.120 .090 .00 \quad 0.04 \quad 0.000 .00896761867 \quad 0.040 .18$ 0.00 ;

luiden 'to sound' 6.570 .62800 .000 .000 .000 .000 .000 .008345896370 .040 .00 0.00 ;

melden 'to report' 6.400 .64300 .000 .000 .000 .000 .000 .005975638670 .000 .00 0.00

peinzen 'to think' 4.860 .23500 .040 .090 .400 .090 .090 .008019566610 .040 .00 0.20 ;

plagen 'to tease' 5.370 .00800 .000 .000 .000 .040 .090 .007038115660 .000 .00 0.00 ;

plegen 'to commit' 5.210 .00800 .000 .000 .000 .000 .000 .005844475730 .000 .00 0.00 ;

plonzen 'to splash' 3.690 .64300 .290 .270 .600 .080 .000 .209168718670 .000 .00 0.00 ;

pluizen 'to give off fluff' 1.100 .23500 .120 .180 .200 .130 .100 .008898085990 .04 0.090 .00 ;

pogen 'to try' 5.350 .00800 .040 .000 .000 .090 .000 .008297865910 .040 .180 .00 ; proeven 'to taste' 5.670 .22200 .000 .180 .000 .040 .090 .007609118090 .000 .00 0.00 ;

razen 'to rage' $5.36 \quad 0.2350 \quad 0.00 \quad 0.00 \quad 0.00 \quad 0.040 .00 \quad 0.009049596020 .040 .09$ 0.00 ;

redden 'to save' $6.600 .86500 .000 .000 .00 \quad 0.000 .00 \quad 0.006528105280 .000 .00$ 0.00

reizen 'to travel' 6.020 .23500 .000 .090 .000 .000 .180 .008058266380 .040 .00 0.00 ;

roven 'to steal' $3.690 .00800 .040 .000 .00 \quad 0.040 .000 .008469187350 .040 .00$ 0.00 ;

schaden 'to damage' $2.71 \quad 0.62800 .00 \quad 0.000 .00 \quad 0.00 \quad 0.000 .00 \quad 828731604 \quad 0.04$ 0.000 .00 ;

scheiden 'to separate' $5.660 .62800 .00 \quad 0.000 .000 .000 .000 .007316828970 .04$ 0.000 .00 ;

schrobben 'to scrub' 3.140 .86500 .250 .270 .200 .080 .180 .001108105111680 .00 0.000 .00 ;

schroeven 'to screw' 4.700 .22200 .210 .090 .000 .080 .000 .0091210536280 .00 0.00 0.20; 
schudden 'to shake' 8.260 .86500 .000 .000 .000 .000 .000 .007945217440 .040 .00 0.00 ;

slagen 'to succeed' 7.110 .00800 .000 .000 .200 .000 .000 .008828899790 .080 .09 0.00

smeden 'to forge' 3.610 .62800 .000 .000 .000 .040 .000 .008627916810 .000 .00 0.00

smoezen 'to whisper' 2.48 0.23500 .420 .270 .000 .090 .000 .0010959278180 .08 0.000 .00

snoeven 'to swagger' 2.480 .22200 .120 .180 .200 .100 .000 .00992113117000 .17 0.000 .00

spugen 'to spit' 5.420 .00800 .080 .360 .000 .080 .000 .0094612486160 .000 .00 0.20; stoven 'to stew' 1.390 .00800 .040 .000 .200 .000 .100 .00117112299120 .170 .09 0.00 ;

streven 'to strive' 5.380 .00800 .040 .000 .000 .000 .000 .0090384910880 .000 .18 0.00 ;

tergen 'to provoke' 2.480 .04700 .000 .000 .000 .000 .000 .007068417760 .040 .09 0.00

tobben 'to worry' $3.500 .8650 \quad 0.380 .27 \quad 0.40 \quad 0.130 .090 .001207120810610 .04$ 0.000 .00

troeven 'to trump' 1.390 .22200 .120 .000 .200 .130 .000 .0098313759240 .040 .18 0.00

turven 'to tally' 1.100 .12500 .120 .000 .000 .080 .000 .00104211059950 .000 .09 0.20

vegen 'to sweep' 6.970 .00800 .000 .000 .000 .000 .000 .007445936680 .000 .18 0.20

vergen 'to demand' $5.080 .04700 .000 .18 \quad 0.200 .050 .00 \quad 0.0094212188870 .08$ 0.000 .00

vlaggen 'to hang out the flag' 0.000 .04700 .000 .090 .000 .040 .100 .00994960 722.400 .000 .0090 .00 ;

voeden 'to feed' $4.770 .62800 .000 .000 .00 \quad 0.00 \quad 0.000 .008206219710 .000 .00$ 0.00

voegen 'to join' $7.520 .00800 .000 .00 \quad 0.000 .00 \quad 0.00 \quad 0.005857205900 .040 .00$ 0.00

volgen 'to follow' 8.300 .04700 .000 .000 .000 .000 .000 .006127635670 .000 .00 0.00

vrezen 'to fear' $6.650 .2350 \quad 0.08 \quad 0.00 \quad 0.00 \quad 0.050 .00 \quad 0.008687015520 .080 .09$ 0.00 ;

waden 'to wade' 4.420 .62800 .000 .000 .000 .000 .000 .0077458212010 .050 .09 0.00 ;

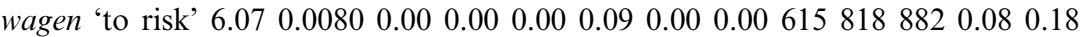
0.00 ;

wenden 'to turn' 7.310 .64300 .000 .000 .000 .000 .000 .208056106130 .000 .00 0.00

wieden 'to weed' 1.950 .62800 .000 .000 .000 .000 .000 .008386768190 .000 .00 0.00 ; 


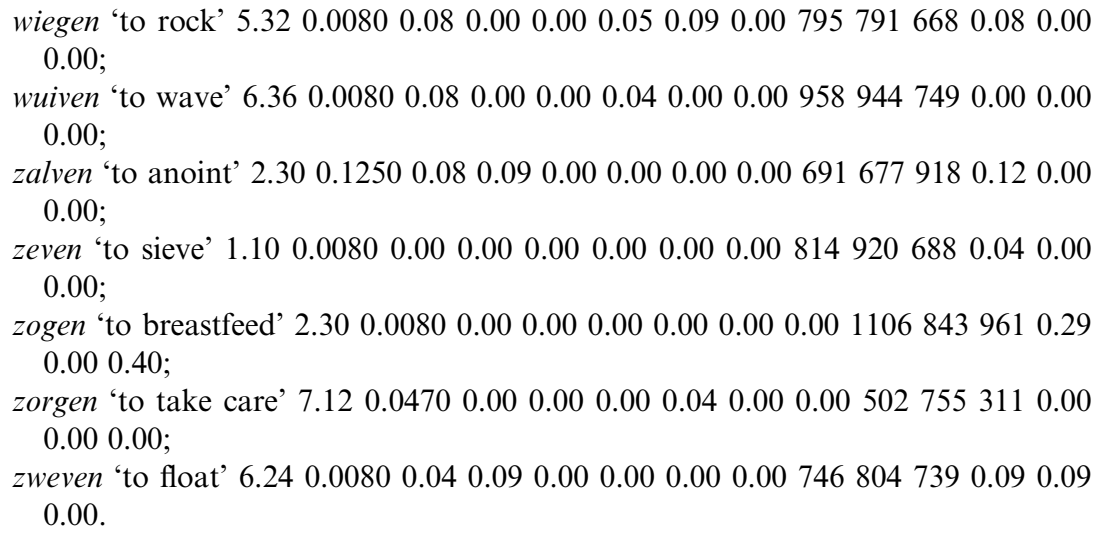

\section{Note}

1. We would like to thank Geert Booij, Rob Schreuder, and Lee Wurm for stimulating discussion and comments. Correspondence address: Max Planck Institute for Psycholinguistics, P.O. Box 310, 6500 AH Nijmegen, The Netherlands. E-mail: mirjam. ernestus@mpi.nl; harald.baayen@mpi.nl.

\section{References}

Albright, Adam; and Hayes, Bruce (2003). Rules vs. analogy in English past tenses: a computational/experimental study. Cognition 90, 119-161.

Anshen, Frank; and Aronoff, Mark (1988). Producing morphologically complex words. Linguistics 26, 641-655.

Aronoff, Mark (1976). Word Formation in Generative Grammar. Cambridge, MA: MIT Press.

Baayen, R. Harald; Burani, Cristina; and Schreuder, Rob (1997). Effects of semantic markedness in the processing of regular nominal singulars and plurals in Italian. In Yearbook of Morphology 1996, Geert Booij and Jaap Van Marle (eds.), 13-34. Dordrecht: Kluwer Academic Publishers.

—; Dijkstra, Ton; and Schreuder, Rob (1997). Singulars and plurals in Dutch: evidence for a parallel dual route model. Journal of Memory and Language 37, 94-117.

-; McQueen, James; Dijkstra, Ton; and Schreuder, Rob (2003). Dutch inflectional morphology in spoken- and written-word recognition. In Morphological Structure in Language Processing, R. Harald Baayen and Rob Schreuder (eds.), 355-390. Berlin and New York: Mouton de Gruyter.

-; Piepenbrock, Richard; and Gulikers, Leon (1995). The CELEX lexical database (CDROM). Philadelphia, PA: Linguistic Data Consortium, University of Pennsylvania.

-; Schreuder, Rob; De Jong, Nivja; and Krott, Andrea (2002). Dutch inflection: the rules that prove the exception. In Storage and Computation in the Language Faculty, Sieb Nooteboom, Fred Weerman, and Frank Wijnen (eds.), 61-92. Dordrecht: Kluwer Academic Publishers. 
-; Tweedie, Fiona J.; and Schreuder, Rob (2002). The subjects as a simple random effect fallacy: subject variability and morphological family effects in the mental lexicon. Brain and Language 81, 55-65.

Berko, Jean (1958). The child's learning of English morphology. Word 14, 150-177.

Boersma, Paul (1996). Praat: Doing Phonetics by Computer. Ms. Amsterdam: University of Amsterdam.

- (1998). Functional Phonology. The Hague: Holland Academic Graphics.

Booij, Geert (1995). The Phonology of Dutch. Oxford: Oxford University Press.

Breiman, Leo; Friedman, Jerome H.; Olshen, Richard A.; and Stone, Charles J. (1984). Classification and Regression Trees, Belmont, CA: Wadsworth International Group.

Bybee, Joan (1985). Morphology: A Study of the Relation between Meaning and Form. Amsterdam: Benjamins.

-(2001). Phonology and Language Use. Cambridge: Cambridge University Press.

Clark, Linda; and Pregibon, Daryl (1992). Tree-based models. In Statistical Methods in S, John M. Chambers and Trevor J. Hastie (eds.), 377-420. Pacific Grove, CA: Wadsworth \& Brooks/Cole.

Daelemans, Walter; Berck, Peter; and Gillis, Steven (1995). Linguistics as data mining: Dutch diminutives. In CLIN V, Papers from the 5th CLIN Meeting, Toine Andernach, Mark Moll and Anton Nijholt (eds.), 59-72. Dept. Computer Science, University of Twente.

-; Gillis, Steven; and Durieux, Gert (1994). The acquisition of stress, a data-oriented approach. Computational Linguistics 20(3), 421-451.

-; Zavrel, Jakub; Van der Sloot, Ko; and Van den Bosch, Antal (2001). TiMBL: Tilburg Memory Based Learner Reference Guide. Version 4.2, Technical Report ILK 02-01, Computational Linguistics, Tilburg University.

Eddington, David (2000). Spanish stress assignment within the analogical modeling of language. Language 76, 92-109.

Ernestus, Mirjam; and Baayen, Harald (2001). Choosing between the Dutch past-tense suffixes -te and -de. In Linguistics in the Netherlands 2001, Ton Van der Wouden and Helen de Hoop (eds.), 81-93. Amsterdam: Benjamins.

-; and Baayen, Harald (i.p.). The functionality of incomplete neutralization in Dutch: The case of past-tense formation. In Papers in Laboratory Phonology 8, Louis M. Goldstein, Douglas H. Whalen, and Catherine T. Best (eds.). Berlin: Mouton de Gruyter.

-; and Baayen, R. Harald (2003). Predicting the unpredictable: interpreting neutralized segments in Dutch. Language 79, 5-38.

Halle, Morris (1973). Prolegomena to a theory of word-formation. Linguistic Inquiry 4, 3-16.

Jaeger, Jeri J.; Lockwood, Alan H.; Kemmerrer, David L.; Van Valin, Robert D.; and Murphy, Brian W. (1996). A positron emission tomographic study of regular and irregular verb morphology in English. Language 72, 451-497.

Jescheniak, Jörg D.; and Levelt, Willem J. M. (1994). Word frequency effects in speech production: retrieval of syntactic information and of phonological form. Journal of Experimental Psychology: Learning, Memory and Cognition 20(4), 824-843.

MacWhinney, Brian; and Leinbach, Jared (1991). Implementations are not conceptualizations: revising the verb learning model. Cognition 40, 121-157.

Manning, Christopher D. (2003). Probabilistic approaches to syntax. In Probability Theory in Linguistics, Rens Bod, Jennifer Hay, and Stefanie Jannedy (eds.), 289-341. Cambridge, MA: MIT Press.

Marcus, Gary (2001). The Algebraic Mind: Integrating Connectionism and Cognitive Science. Cambridge, MA: MIT Press.

-; Brinkman, Ursula; Clahsen, Harald; Wiese, Richard; and Pinker, Steven (1995). German inflection: the exception that proves the rule. Cognitive Psychology 29, 189-256. 
Oldfield, Robert C.; and Wingfield, Arthur (1965). Response latencies in naming objects. Quarterly Journal of Experimental Psychology 17, 273-281.

Pinheiro, José. C.; and Bates, Douglas M. (2000). Mixed-effects models in S and S-PLUS, Statistics and Computing. New York: Springer.

Pinker, Steven (1991). Rules of language. Science 153, 530-535.

- (1997). Words and rules in the human brain. Nature 387, 547-548.

- (1999). Words and Rules: The Ingredients of Language. London: Weidenfeld and Nicolson.

-; and Prince, Alan (1988). On language and connectionism. Cognition 28, 73-193.

-; and Prince, Alan (1991). Regular and irregular morphology and the psychological status of rules of grammar. In Proceedings of the Seventeenth Annual Meeting of the Berkeley Linguistics Society, Laurel A. Sutton, Andrew Dolbey and Christopher Johnson (eds.), 230-251. Berkeley, CA: BLS.

Plaut, David C; and Gonnerman, Laura M. (2000). Are non-semantic morphological effects incompatible with a distributed connectionist approach to lexical processing? Language and Cognitive Processes 15(4/5), 445-485.

Plunkett, Kim; and Juola, Patrick (1999). A connectionist model of English past tense and plural morphology. Cognitive Science 23(4), 463-490.

Ramscar, Michael (2002). The role of meaning in inflection: why the past tense doesn't require a rule. Cognitive Psychology 45, 45-94.

Rumelhart, David E.; and McClelland, James L. (1986). On learning the past tenses of English verbs. Parallel Distributed Processing. Explorations in the Microstructure of Cognition, Vol. 2, 216-271. Cambridge, MA: MIT Press.

Sandra, Dominiek; Frisson, Steven; and Daems, Frans (1999). Why simple verb forms can be so difficult to spell: the influence of homophone frequency and distance in Dutch. Brain and Language 68(1/2), 277-283.

Seidenberg, Mark S.; and Gonnerman, Laura M. (2000). Explaining derivational morphology as the convergence of codes. Trends in Cognitive Sciences 4(9), 353-361.

-; and Hoeffner, James H. (1998). Evaluating behavioral and neuroimaging data on past tense processing. Language 74, 104-122.

Skousen, Royal (1989). Analogical Modeling of Language. Dordrecht: Kluwer.

- (1993). Analogy and Structure. Dordrecht: Kluwer.

Trommelen, Mieke; and Zonneveld, Wim (1979). Inleiding in de generatieve fonologie. Muiderberg: Coutinho.

Wetzels, Leo (1982). Anologie et lexique: le problème de l'opacité en phonologie générative. Doctoral dissertation, University of Nijmegen.

Zonneveld, Wim (1993). Lexical and phonological properties of Dutch voicing assimilation. In Sound Structures: Studies for Antonie Cohen, Marcel van den Broecke; Vincent van Heuven, and Wim Zonneveld (eds.), 101-135. Dordrecht: Foris. 
